\title{
Preparation and Characterization of Biobased Poly(Ethylene- 2,5-Furan Dicarboxylate)/Clay Nanocomposites
}

\author{
${ }^{1}$ M. B. Nasirudeen, ${ }^{2}$ H. C. Hailes and 2 J. R. G. Evans \\ 1Department of Chemistry, Federal University Lafia P.M.B. 146, Lafia Nasarawa State Nigeria \\ 2Department of Chemistry, University College London 20 Gordon Street, WC1H OAJ, London, United Kingdom \\ [Corresponding Author: E-mail: n.m.baba.10@alumni.ucl.ac.uk, D: +234 (0) 8036286538]
}

\section{ABSTRACT}

Poly(ethylene 2,5-furan dicarboxylate)/Clay nanocomposites was prepared via esterification and polycondensation reaction. Biobased monomer was first intercalated into the interlayer regions of clay minerals by ion exchange reaction. Then, the clay was dispersed in the monomer at different loading degrees to conduct the polymerization process. Polymerization through the interlayer of the clay led to the exfoliated poly(ethylene-2,5-furan dicarboxylate)/montmorillonite nanocomposite formation. X-ray diffraction (XRD) analysis revealed that the resultant nanocomposites exhibited exfoliated polymer/clay nanocomposites

Keywords: Poly(ethylene-2,5- furan dicarboxylate); renewable polymers; nanocomposites, montmorinollite

\section{INTRODUCTION}

Research on nanocomposites derived from biodegradable polyesters and layered silicates have been a subject of great interest from the scientific community in recent years (Alexandre and Dubois, 2000, Kumar and Nanthini, 2009, Zhu et al., 2013). This is because layered clays such as Montmorillonite (MMT) are environmentally friendly, naturally abundant, and thus available at relatively low cost. Their dispersion within polyester matrices provides significant improvement in various properties, in contrast with the biodegradable polymers, which widens the application areas of these biopolyesters (Chen et al., 2008).

Polyester-layered silicate nanocomposites can be made by three different methods: polymer melt intercalation, solution adsorption/ intercalation and in situ intercalative polymerization (Chen and Evans, 2005, Chouli et al., 2012, Ray and
Okamoto, 2003). Chemicals from renewable feedstock have been proposed as monomers for polymer production and among the bio resources, carbohydrates which are obtained from the biorefinery can be transformed into varieties of products, including dehydrosugars, furans, and levulinic acid by dehydration. 2,5furandicarboxylic acid (2,5-FDCA) is an important member of the furan family that can be formed by an oxidative dehydration of glucose (Werpy et al., 2004). For instance, 2,5-FDCA has a similar structure to teraphthalic acid (Figure 1) that is used in the production of polyethylene terephthalate (PET). Therefore, 2,5-FDCA has been found to be an alternative for the petroleumbased terephthalic acid (Bokanga, 1996, Nasirudeen et al., 2017). Furthermore, the US department of Energy has also identified 2,5FDCA as one of the 12 top potential chemicals that can be derived from biomass (Holladay et al., 2004).
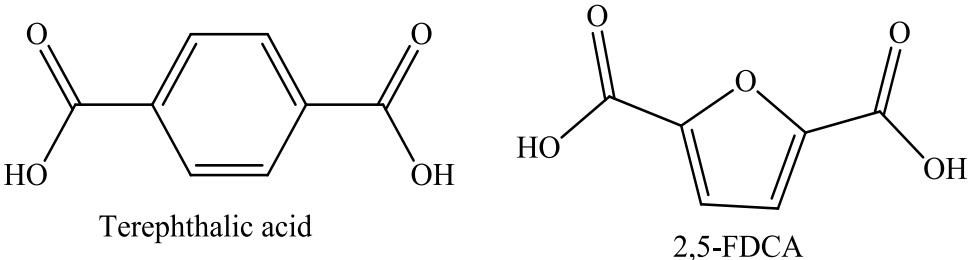

Figure 1. Structural similarity between terephthalic acid and 2,5-FDCA 
Therefore, 2,5-FDCA has an enormous potential as a replacement for terephthalic acid, for the synthesis of various polyesters, such as poly(ethylene terephthalate) (PET), poly(propylene terephthalate) (PPT) and poly(butylene terephthalate) (PBT). PEF is the most studied and most important polyester from 2,5-FDCA and advantage of this biobased polymer as a PET analog provided an essential opportunity to address a high volume, high value chemical market. Roughly, 56 million tons of PET are manufactured every year leading to a market value of PET plastic in the range of $\$ 1.00$ $3.00 / \mathrm{lb}$, depending on its usage (Yoshida et al., 2016).

Biobased polymers derived directly from biomass are generally polysaccharides which are carbohydrates formed through the condensation of monosaccharide residues by hemi-acetal or hemi-ketal linkages. They can also be found as a short oligosaccharide sequence or polymeric repeat units linked to other biopolymers and serve as energy storage, structural and protective components, and for gel formation depending on their specific chemical structure, composition, molecular weight and ionic character (Alexandre and Dubois, 2000, Ramesh and Tharanathan, 2003). The major classes of polysaccharides are starches, celluloses and chitin which constitutes the bulk of polymers directly derived from biomass and are used in food and non-food industries due to their functional diversities (Ramesh and Tharanathan, 2003). Although they are naturally obtained directly from biomass, they generally need to have a bulk or surface modification chemically on the hydroxyl groups in their structure to pave the way for their application as biopolymers. In terms of bulk modification, some derivatives of these polymers are also desirable: an example of such a process is the formation of chitosan and the chemical modification involves the compatibility and minimization of the hydrophilicity of natural fibres between the fibres and the matrix (Gandini, 2008). Therefore, polysaccharides are generally modified for used as biopolymers by reducing their hydrophilicity; achieved by lowering their surface energy or creating enough surface morphology in order to obtain a water contact angle higher than $90^{\circ}$ (Cunha and Gandini, 2010, Gandini, 2008, Gandini, 2011). In this research work, preparation and characterization of biobased poly(ethylene 2,5-furan dicarboxylate)/clay nanocomposites is reported.

\section{MATERIALS AND METHODS Materials}

Potassium per manganate, hydrochloric acid, titanium (iv) n-butoxide, triflouroacetic acid, 1,2dichlorobenzene and 1,4-butandiol were purchased from Signa-Aldrich, Gilligham Dorset UK at $99 \%$ purity and montmorillorite clay (Nanofill 116) was obtained from Southern Clay products, UK. The 5-hydromethylfuran (5-HMF) used was our purified product synthesized previously (Nasirudeen et al., 2017) . All other reagents were used as received without further purification.

\section{Methods}

Synthesis of 2, 5-Furandicarboxylic acid (2,5 FDCA)

2,5-FDCA was synthesized according to the following procedure (Ma et al., 2012). Briefly, 5hydroxymethyl furan (5-HMF) $(1.26 \mathrm{~g}, 10 \mathrm{mmol})$ was added to a solution of sodium hydroxide (920 $\mathrm{mg}, 23 \mathrm{mmol}$ ) in a $100 \mathrm{ml}$ round bottom flask equipped with magnetic stirrer. Potassium permanganate $(363.5 \mathrm{mg}, 2.3 \mathrm{mmol})$ was added to the contents in the $100 \mathrm{ml}$ flask and stirred for $0.5 \mathrm{~h}$ at ambient temperature. The mixture was filtered and $1 \mathrm{~mL}$ of concentrated $\mathrm{HCl}$ was added to the filtrate, precipitate was formed and the $\mathrm{pH}$ was adjusted to 1 or less. The precipitate was washed with distilled water and a pale yellow solid was isolated by filtration and dried in a vacuum. The product was characterized by FTIR, ${ }^{1} \mathrm{H}$ NMR and ${ }^{13} \mathrm{C}$ NMR spectroscopy.

\section{Synthesis of polyester from 2,5-FDCA}

Polymerization was performed based on the method described by Ma, et al., (2012). Briefly, 2,5-FCDA (4.682 g $30 \mathrm{mmol}$ ), 1, 4-butandiol 
(13.523 $\mathrm{g}, 150 \mathrm{mmol}$ ) and titanium (IV) $\mathrm{n}$ butoxide $(0.102 \mathrm{~g},(0.3 \mathrm{mmol})$ were charged into a $50 \mathrm{~mL}$ round bottom flask fitted with a magnetic stirrer. The reaction flask was immersed into an oil bath heated at $160{ }^{\circ} \mathrm{C}$ for $6 \mathrm{~h}$ under $\mathrm{N}_{2}$ atmosphere. After $6 \mathrm{~h}$ of reaction time, the excess diol was removed under vacuum and the reaction continued at $200{ }^{\circ} \mathrm{C}$ for further $2 \mathrm{~h}$ under vacuum. Upon cooling to room temperature, $6 \mathrm{~mL}$ of 1,2-dichlorobenzene was added to the reaction flask and heating continued at $200{ }^{\circ} \mathrm{C}$ under vacuum to remove traces of diol by azeotropic distillation with 1,2-dichlorobenzene. The resulting polyester was dissolved in $30 \mathrm{~mL}$ of triflouroacetic acid (TFA) and precipitated in $300 \mathrm{~mL}$ methanol. The precipitates were centrifuged at $3000 \mathrm{rpm}$ for 10 minutes, washed with methanol $(5 \mathrm{~mL}, 3$ times) and dried at $50{ }^{\circ} \mathrm{C}$ under vacuum overnight and characterised by FTIR, ${ }^{1} \mathrm{H}$ NMR, ${ }^{13} \mathrm{NMR}$, $\mathrm{XRD}$ and by elemental analysis.

\section{Treatment of montmorillonite clay with 2,5- FDCA}

A suspension of $1 \mathrm{~g}$ of montmorillonite clay (Nanofill 116) was made in $25 \mathrm{~mL}$ of ethyl acetate in a glass bottle with lid and $2 \mathrm{~g}$ of 2,5-FDCA was added. The contents were stirred with the aid of an ultrasonic probe (U200s control, IKA Labortechnik Germany) at 0.5 duty cycle, $60 \%$ amplitude and poured into a Petri dish and left to stand for $86 \mathrm{ks}(24 \mathrm{~h})$ for drying. Control samples were prepared with solvent but without 2,5FDCA.

Dispersive intercalation of clay and 2,5-FDCA $1 \mathrm{~g}$ of montmorillonite clay was dissolved in 25 $\mathrm{mL}$ of DMSO in a $50 \mathrm{~mL}$ glass bottle and dispersed with an ultrasonic probe at 0.5 duty cycle, $60 \%$ amplitude for 20 minutes. To the contents in the $50 \mathrm{~mL}$ glass bottle, $2 \mathrm{~g}$ of 2,5FDCA were added and the dispersion continued for further 20 minutes. The contents were poured into an evaporating basin and placed on a hot plate pre-set at $150^{\circ} \mathrm{C}$ to evaporate the DMSO. After 30 minutes, the evaporating basin was cooled to room temperature and dried in a vacuum oven at $60{ }^{\circ} \mathrm{C}$ for $72 \mathrm{~h}$.
Melt intercalation of clay and 2,5-FDCA Montmorillonite clay and 2,5-FDCA were weighed in a ratio of $1: 2$ and placed into a $400 \mathrm{~mL}$ cylindrical glass vessel. Nitrogen gas was introduced into the glass vessel with the aid of a balloon as inlet and an empty balloon was placed at the outlet. The contents were heated in a furnace to $330-344^{\circ} \mathrm{C}$ and allowed to cool to room temperature.

Preparation of Poly(ethylene-2,5-furan dicarboxylate)/Clay nanocomposites

Poly(ethylene-2,5-furan dicarboxylate/clay nanocomposites was prepared by intercalation from solution, in situ intercalative polymerization and melt intercalation as follows:

\section{Intercalation method}

Montmorillonite clay $(10 \mathrm{mg})$ was weighed and dispersed in chloroform (25 mL) by ultrasonification. Polyester $(200 \mathrm{mg})$ was added to the clay solution and dispersed for a further 30 minutes. The contents were transferred into a Petri dish and dried in a fume cupboard overnight to evaporate the chloroform. After drying, the mixture was ground with a pestle and mortar to a fine powder and the XRD pattern of the polyester/clay was obtained.

\section{In situ intercalative polymerization}

2,5-FDCA ( $4.5 \mathrm{~g})$, montmorillonite clay $(0.225 \mathrm{~g})$, 1,4-butandiol (13.53 g, $30 \mathrm{mmol})$ and titanium (IV) n-butoxide were charged into a $50 \mathrm{~mL}$ round bottom flask and heated in an oil bath set at $160^{\circ} \mathrm{C}$ under reflux and in a $\mathrm{N}_{2}$ atmosphere for 6 $\mathrm{hr}$. The excess diol was removed under vacuum and the reaction continued for further $2 \mathrm{hr}$ at 200 ${ }^{\circ} \mathrm{C}$ under vacuum. The reaction mixture was cooled at room temperature and the resulting polyester was dissolved in triflouroacetic acid (30 $\mathrm{mL}$ ). Methanol (100 $\mathrm{mL}$ was added to precipitate the polyester/clay and the precipitate was centrifuged at $300 \mathrm{rpm}$ for 10 minutes, washed with methanol (10 $\mathrm{mL} 3$ times) and dried under vacuum at $50^{\circ} \mathrm{C}$ overnight. 


\section{Melt intercalation}

Montmorillonite clay $(10 \mathrm{mg})$ and polyester $(200$ $\mathrm{mg}$ ) were charged into a $50 \mathrm{~mL}$ round bottom flask and heated at $40{ }^{\circ} \mathrm{C}$ with constant stirring at $300 \mathrm{rpm}$ for 30 minutes. The melt sample was cooled to $4{ }^{\circ} \mathrm{C}$ and ground with a pestle and mortar to a fine powder and analyzed by XRD.

\section{Characterization}

${ }^{1} \mathrm{H}$ and ${ }^{13} \mathrm{C}$ NMR were recorded using a Bruker AMX $300 \mathrm{MHz}$ spectrometer and data were processed by ACD/NMR Processor Academic Edition. Samples were made as dilutions of $\mathrm{CDCl}_{3}$ unless otherwise stated. All chemical shifts (ठ) are reported in parts per million (ppm). Multiplicities for ${ }^{1} \mathrm{H}$ coupled signals are denoted as $\mathrm{s}=$ singlet, $\mathrm{d}=$ doublet, $\mathrm{t}=$ triplet, $\mathrm{q}=$ quartet, quin = quintet, $\mathrm{m}=$ multiplet. Coupling constants $(J)$ are reported in Hertz $(\mathrm{Hz})$. FTIR spectra were obtained in this work using ALPHA Bruker Optics FTIR spectrophotometer equipped with ZnSe ATR crystal.

For XRD analysis, the samples prepared from 5HMF and 2,5-FDCA by the solution and melt intercalation methods were carefully ground into fine powders using a pestle and mortar and pressed with a microscope slide into a copper sample holder and analysed using an X-ray diffractometer (Siemens D500) in the Chemistry Department of UCL using $\mathrm{Cu} \mathrm{Ka1}$ radiation with wavelength of $0.154056 \mathrm{~nm}$. The diffractometer running at $40 \mathrm{kV}$ and $30 \mathrm{~mA}$ was set at a low initial angle of $2^{\circ}$ and scanned to $25^{\circ} 2 \theta$ in $0.05^{\circ}$ steps. Counts were collected for $6 \mathrm{~s}$ at each step and the XRD pattern of the samples was obtained.

\section{RESULTS AND DISCUSSION}

Structure characterization of FDCA

2,5-FDCA was synthesized from 5-HMF using potassium permanganate in a solution of sodium hydroxide and a pale-yellow solid was isolated by filtration as the product. The product was characterized by FT-IR and the result is presented in Figure 2.

From this result, the expected absorption bands of the characteristic functional groups associated with this compound such as stretching and bending absorption bands were observed. For instance, $\quad \mathrm{C}=0$ stretching vibration characteristics of carbonyl group occurs at 1666 $\mathrm{cm}^{-1}$ and based on literature data, the absorption resulting from $\mathrm{C}=\mathrm{O}$ stretching of carboxylic acids occurs near $1760 \mathrm{~cm}^{-1}$ (Silverstein et al., 2005a, Silverstein et al., 2005b). This decrease may be attributed to the conjugation effects of the carbonyl group with the unsaturation of the furan ring. Furthermore, some absorption bands were observed in the $2800-2200 \mathrm{~cm}^{-1}$ region associated with carboxylic acids and these may be as a result of the very intensive $\mathrm{O}-\mathrm{H}$ stretching absorption. Also observed on the FT-IR spectrum are: $\mathrm{C}-\mathrm{O}$ stretching and $\mathrm{O}-\mathrm{H}$ bending which appears at 1270 and $1418 \mathrm{~cm}^{-1}$ respectively. The main peaks observed in the spectra are summarized in Table 1.

Table 1. Characteristic peaks of FDCA.

\begin{tabular}{ll}
\hline Assignment & Wavenumber $/ \mathrm{cm}$ \\
\hline $\mathrm{C}=\mathrm{O}$ (Carboxylic acid) & 1666 \\
$\mathrm{OH}$ (Acid) & $2700-3400$ \\
$\mathrm{C}=\mathrm{C}$ (Furan ring) & 1569 \\
$\mathrm{C}-\mathrm{O}-\mathrm{H}$ bending (Acid) & 1418 \\
$\mathrm{C}-\mathrm{H}$ bending and Furan ring & $960,849,760$ \\
\hline
\end{tabular}




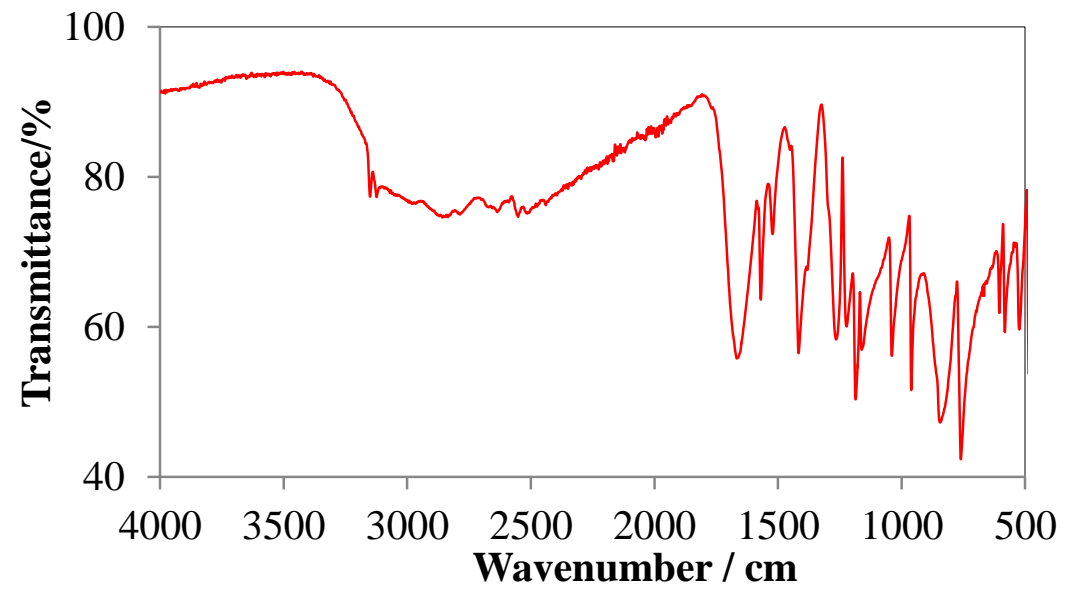

Figure 2. FT-IR Spectra of prepared FDCA.

Other vibrations that are associated with 2, 5disubstituted furans were observed at $3149 \mathrm{~cm}^{-1}$ which may be as a result of $\mathrm{O}-\mathrm{H}$ stretching of the carboxylic acid and also $\mathrm{C}-\mathrm{H}$ stretching vibration at $\mathrm{C}-3,4$ positions. Another characteristic band occurs at $1569 \mathrm{~cm}^{-1}$ which results from $\mathrm{C}=\mathrm{C}$ stretching absorptions and at $1039 \mathrm{~cm}^{-1}$ which corresponds to the characteristic band of heterocyclic breathing. Furthermore, bending motions that are typical of 2, 5-disubstituted furan were observed at 960,843 and $759 \mathrm{~cm}^{-1}$ respectively. All these characteristic absorptions were similar to those peaks reported elsewhere (Gandini et al., 2009a, Gandini et al., 2009b, Mitiakoudis and Gandini, 1991, Silverstein et al., 2005a, Silverstein et al., 2005b).

The structure of the synthesized FDCA was further characterized by ${ }^{1} \mathrm{H}$ NMR and ${ }^{13} \mathrm{C}$ NMR and the results are presented in Figures 3 and 4 . From Figure 3 , it can be seen that a singlet peak was observed at $7.29 \mathrm{ppm}$ and this can be due to the proton resonances from $\mathrm{H}-3$ and $\mathrm{H}-4$ protons of the furan ring. Also observed on the spectra is the proton resonance associated with carboxylic acid group at $13.56 \mathrm{ppm}$. These results are in agreement to those reported in literature (Gandini et al., 2009a, Gandini et al., 2009b, Silverstein et al., 2005a).

The result of the ${ }^{13} \mathrm{C}$ NMR for the FDCA is presented in Figure 4. It can be observed that a peak appeared at $118.31 \mathrm{ppm}$ that corresponds to the resonances of $\mathrm{C} 3$ and $\mathrm{C} 4$ of the furan ring while that at $146.92 \mathrm{ppm}$ may be due to the resonances of $\mathrm{C} 2$ and $\mathrm{C} 5$. This is because these chemical shifts are characteristic of those associated with 2, 5-disubsituted furan rings (Gandini et al., 2009a). Also, a ${ }^{13} \mathrm{C}$ chemical shift associated with carboxylic acids usually occurs at $150-185 \mathrm{ppm}$. This peaks associated the carboxylic acid were observed at 158.47 and 149.41 ppm, respectively.

\section{Polymerization Process}

The polymerization reaction was conducted by the esterification method and followed by polycondensation reaction (Scheme 1), and at the end of the polymerization process, a fibrous lumps of polymer were obtained. The resulting polymer was characterized by NMR, FTIR and TGA.

\section{NMR structure characterization}

The ${ }^{1} \mathrm{H}$ NMR and ${ }^{13} \mathrm{C}$ NMR spectra for the polymer product are presented in Figures 5 and 6 . From Figure 5, it can be observed that the resonance peaks of $\mathrm{H} 3$ and $\mathrm{H} 5$ of the furan protons appeared at $7.19 \mathrm{ppm}$ and that at 4.38 is attributed to that of the ester $-\mathrm{OCH}_{2}$ Also observed are two $\mathrm{CH}_{2}$ next to the $\mathrm{OCH}_{2}$ at 1.89 ppm. 


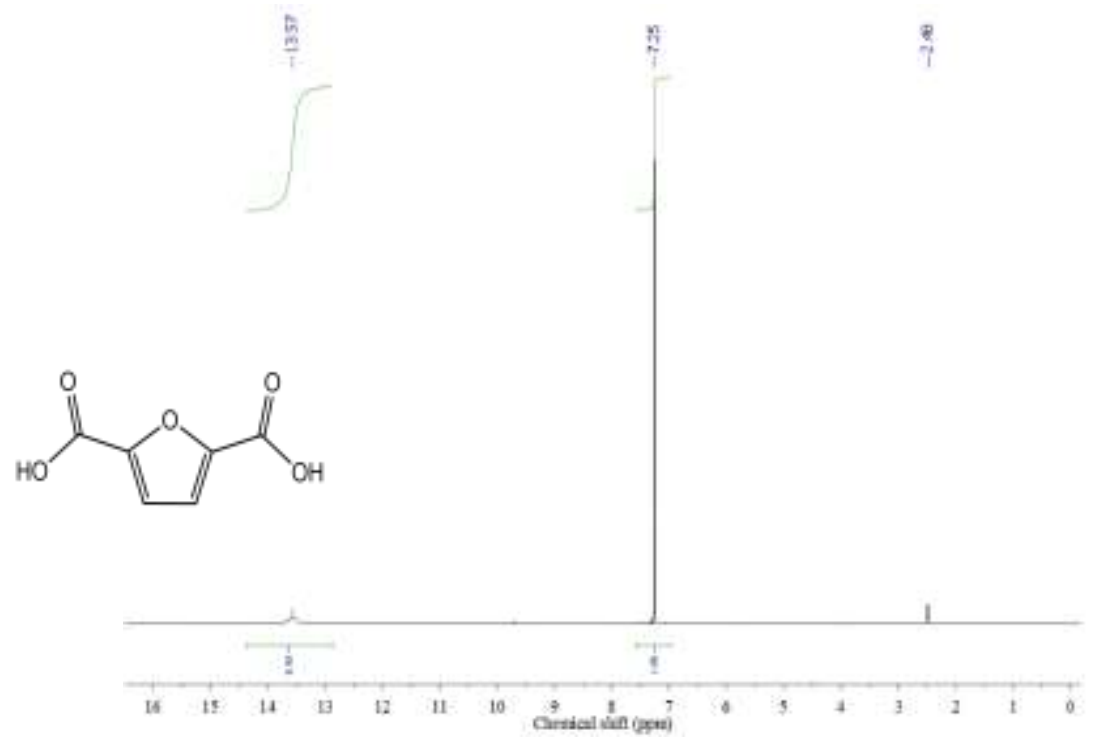

Figure 3: ${ }^{1} \mathrm{H}$ NMR of FDCA in DMSO-d $6(500 \mathrm{MHz})$

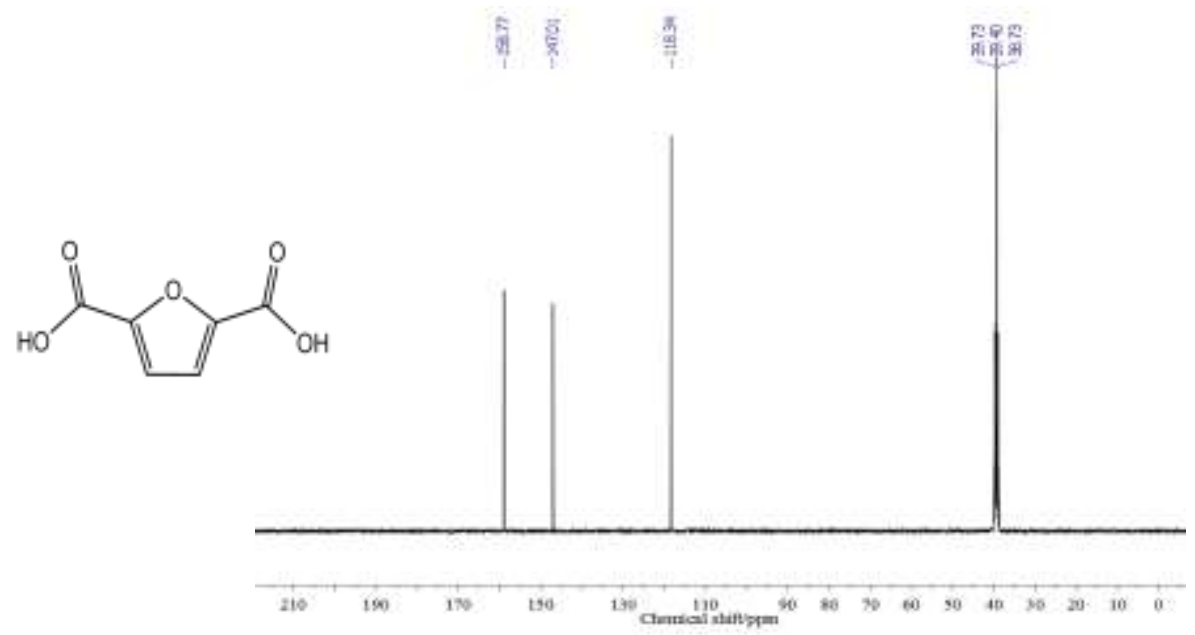

Figure 4: ${ }^{13} \mathrm{C}$ NMR of FDCA in DMSO- $\mathrm{d}_{6}(500 \mathrm{MHz})$

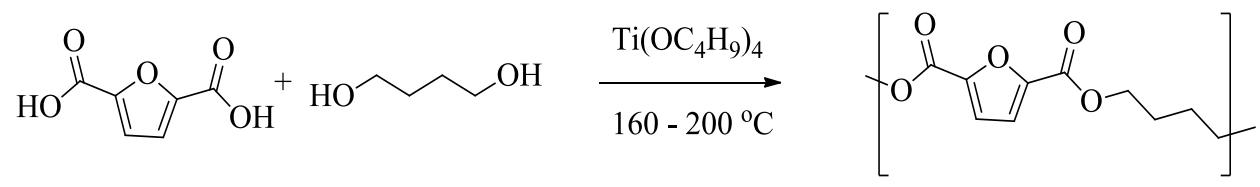

Scheme 1. Synthesis of poly (butylene-2, 5-furandicarboxylate)

In the ${ }^{13} \mathrm{C}$ NMR as shown in Figure $6, \mathrm{C}=0$, $\mathrm{C} 2 / \mathrm{C} 5$ and $\mathrm{C} 3 / \mathrm{C} 4$ associated with the furan ring were observed at 157.99, 146.75 and 118.51 ppm, respectively. Also observed on the spectra are the carbon atoms associated with the ester at 64.94 and $25.24 \mathrm{ppm}$. Since the diol used is 1, 4butane diol, the ester group is represented here as $-\mathrm{COOCH}_{2}-\left(\underline{\mathrm{CH}}_{2}\right)_{2}-\mathrm{CH}_{2} \mathrm{O}$-. Therefore, $\underline{\mathrm{C}}$ is the expected at $64.95 \mathrm{ppm}$ and $C$ at $25.24 \mathrm{ppm}$. These resonances were all comparable to those reported elsewhere (Ma et al., 2012b).

From these results, it could be concluded that the furan ring remained thermally stable in the final product despite the extensive heating at $200{ }^{\circ} \mathrm{C}$ during the polymerization reaction. 


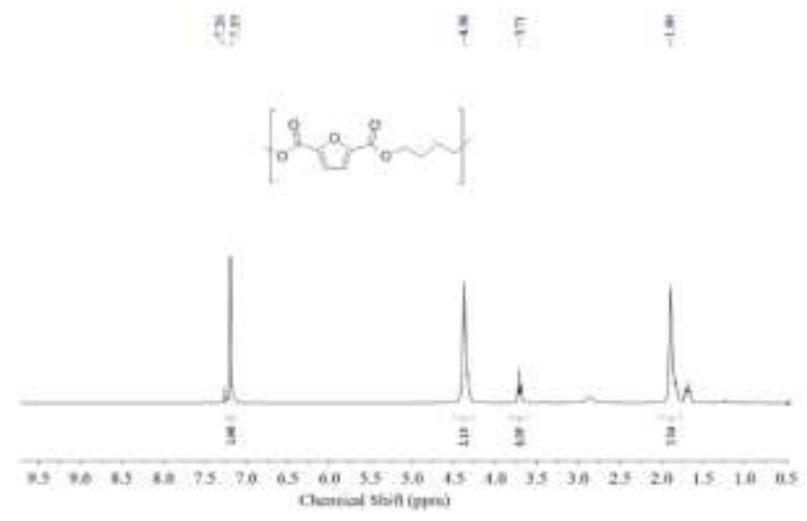

Figure 5: ${ }^{1} \mathrm{H}$ NMR spectra of polyester from FDCA and 1, 4-butanediol in $\mathrm{CDCl}_{3}$

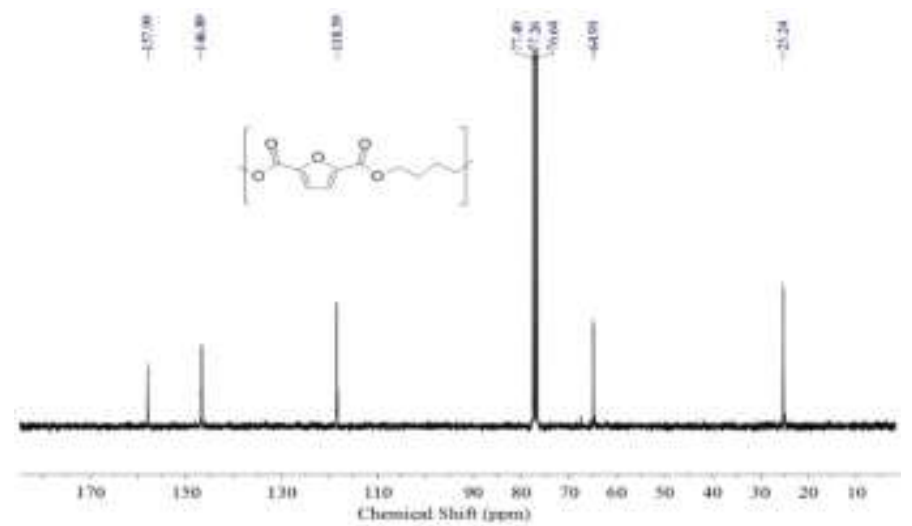

Figure 6: ${ }^{13} \mathrm{C}$ NMR spectra polyester from FDCA and 1, 4-butanediol

\section{FT-IR structure characterization}

The resulting polyester synthesized from FDCA and 1, 4-butanediol was characterized by FTIR. The FTIR spectra shown in Figure 7 provided evidence for the chemical structure of the polyester. Characteristic absorptions of the furan ring at 3122, 1574, 1039, 975, 824 and $771 \mathrm{~cm}^{-1}$, and those of the ester carbonyl at $1728 \mathrm{~cm}^{-1}$ were all observed. This also confirmed the results obtained from the NMR spectrum. The detailed functional group assignments are presented in Table 2.

To ascertain the total elimination of the 1,4butanediol from the polyester, the FTIR spectrum of 1,4-butanediol was compared with that of the polyester product as shown in Figure 8 and it can be seen that the absorption band of the $\mathrm{OH}$ group present on the 1,4-butanediol spectra was absent on the polyester. This indicates that the polymerization reaction proceeds and the expected product was obtained.

\section{XRD pattern of the polymer/clay nanocomposites}

Assessments of intercalation and/or exfoliation of the polymer clay nanocomposites were investigated by XRD and the results are presented in Figure 9. From these results, it can be observed that the basal spacing $\left(\mathrm{d}_{001}\right)$ of the polymer-clay nanocomposite produced by an in situ polymerization is $1.413 \mathrm{~nm}$. This revealed a decrease in the d-spacing when compared with that of the FDCA monomer $(1.70 \mathrm{~nm})$ and this suggests an exfoliation of the polymer into the clay galleries based on the basal spacing. Also, it was observed that the $d_{001}$ value of the polymer without the clay was absent in relation to its nanocomposite counterpart. Therefore, from this result it can be concluded that an exfoliated polymer/clay nanocomposite was prepared by an in situ polymerization technique. 


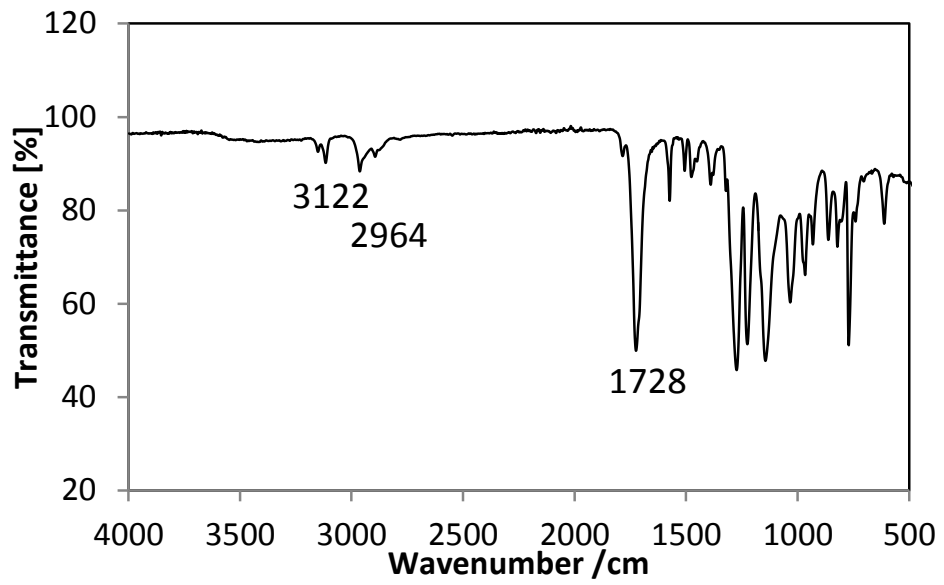

Figure 7: FTIR spectrum of polyester from FDCA

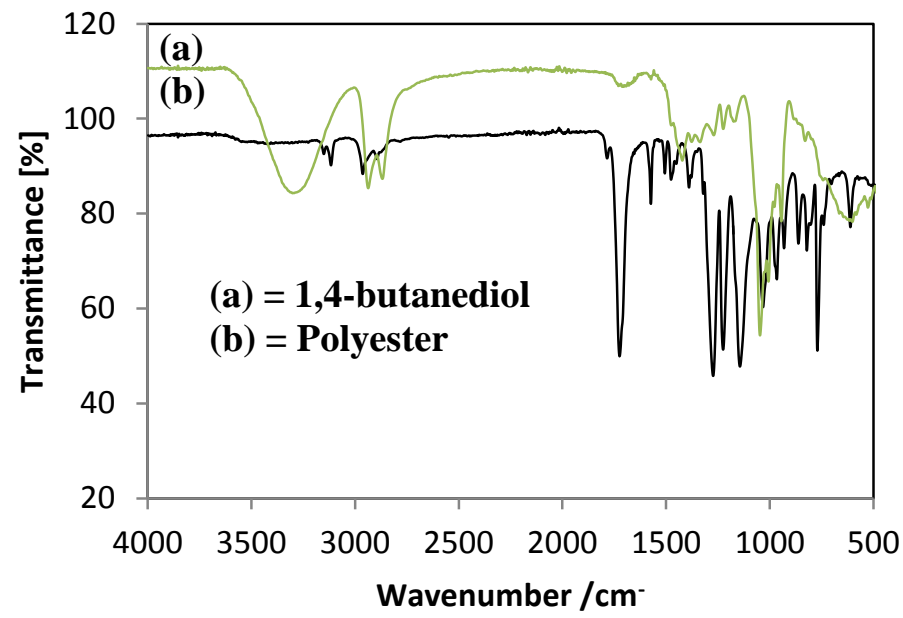

Figure 8: FTIR spectrum of (a) 1, 4-butanediol and (b) FDCA/BD polymer

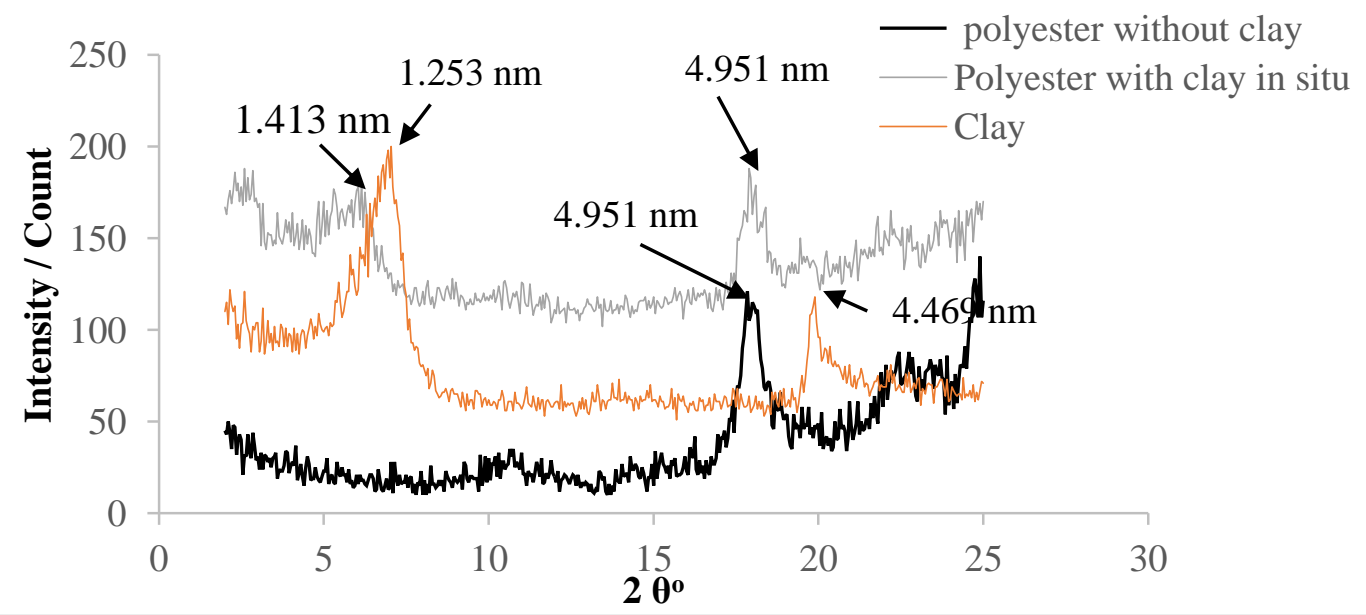


Figure 9: XRD pattern polyester with and without clay

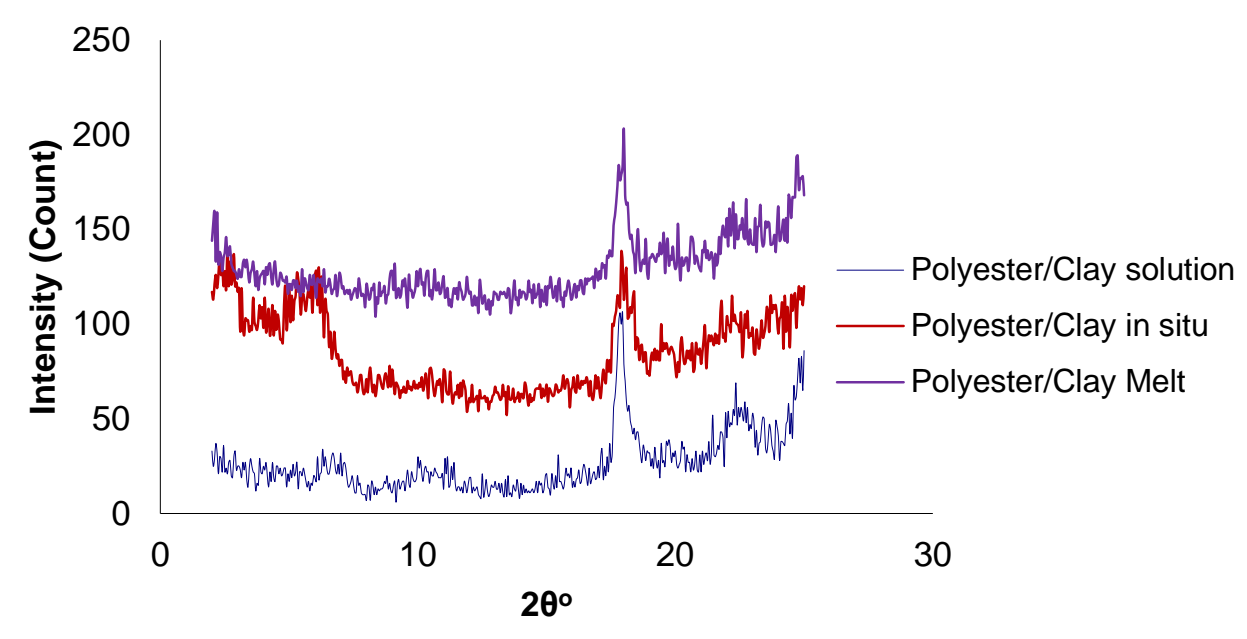

Figure 10: XRD pattern of polyesters/clay nanocomposites produced by various methods

Table 2: FT-IR absorption bands of polyester from FDCA

\begin{tabular}{ll}
\hline Assignment & Wavenumber/cm \\
\hline$=\mathrm{CH}$ & 3122 \\
$\mathrm{C}-\mathrm{H}$ & 2964,2894 \\
$\mathrm{C}=\mathrm{O}$ & 1724,1785 \\
$\mathrm{C}=\mathrm{C}$ & 1574 \\
$\mathrm{C}-\mathrm{O}$ & 1272 \\
Furan breathing & 1039 \\
Furan bending & $975,824,771$ \\
motion & \\
\hline
\end{tabular}

\section{XRD pattern of polymer/ Clay nanocomposites by different methods}

The XRD patterns of polyester/clay nanocomposites as presented in Figure 10 revealed that there was no observed changes on polymer/clay nanocomposites produced by solution and melt intercalative methods. This might be due to the inability of these nanocomposite to form a thermodynamically homogeneous mixtures of the clay and polymer matrix. On the other hand, a slight increased on the $\mathrm{d}$-spacing was observed in in situ polymerization with a $2 \theta$ value of $6.25^{\circ}$ and this suggests that the substrate used led to the formation of a polymer- clay nanocomposite.

\section{CONCLUSION}

In this study, biobased poly(ethylene- 2,5-furan dicarboxylate)/clay nanocomposites was prepared. The results obtained showed that an exfoliated polyester/clay nanocomposites were prepared by solution, in situ and melt intercalated methods as revealed by XRD chromatograms. Also, the interaction between the monomers and $\mathrm{Na}$-montmorillonite clay showed that 5-HMF and 2,5-FDCA were able to intercalate between the clay layers which suggests that the production of polymer-clay nanocomposites are possible based on the in-situ polymerization of intercalated monomers and confirmed that the polymerization process produced the polyester accompanied by increased basal spacing of the montmorillonite, confirming that poly(ethylene- 2,5-furan dicarboxylate)/clay. 


\section{ACKNOWLEDGEMENT}

The authors wish to thank Mr. Martins Vicker for his technical assistance in the provision of the XRD spectra. The financial support by the Tertiary Educational Trust Fund of Nigeria (TETFUND) is highly appreciated.

\section{REFERENCES}

Alexandre, M. and Dubois, P. (2000). PolymerLayered Silicate Nanocomposites: Preparation, Properties and Uses of a New Class of Materials. Materials Science \& Engineering R-Reports, 28, 1 63.

Bokanga, M. (1996). Biotecnology and Cassava Processing in Africa. IITA Research, 12, 14-18.

Chen, B. and Evans, J. R. G. (2005). Thermoplastic Starch-Clay Nanocomposites and Their Characteristics. Carbohydrate Polymers, 61, 455-463.

Chen, B., Evans, J. R. G., Greenwell, H. C., Boulet, P., Coveney, P. V., Bowden, A. A. and Whiting, A. (2008). A Critical Appraisal of Polymer-Clay Nanocomposites. Chemical Society Reviews, 37, 568-594.

Chouli, F., Benyoucef, A., Yahiaoui, A., Quijada, C. and Morallon, E. (2012). A Conducting Nanocomposite Via Intercalative Polymerisation of 2-Methylaniline with Aniline in Montmorillonite CationExchanged. Journal of Polymer Research, 19: 3.

Cunha, A. G. and Gandini, A. (2010). Turning Polysaccharides into Hydrophobic Materials: A Critical Review. Part 1. Cellulose. Cellulose, 17, 875-889.

Gandini, A. (2008). Polymers from Renewable Resources: A Challenge for the Future of Macromolecular Materials. Macromolecules, 41, 9491-9504.

Gandini, A. (2011). The Irruption of Polymers from Renewable Resources on the Scene of Macromolecular Science and
Technology. Green Chemistry, 13, 10611083.

Gandini, A., Coelho, D., Gomes, M., Reis, B. and Silvestre, A. (2009a). Materials from Renewable Resources Based on Furan Monomers and Furan Chemistry: Work in Progress. Journal of Materials Chemistry, 19, 8656-8664.

Gandini, A., Silvestre, A. J. D., Neto, C. P., Sousa, A. F. and Gomes, M. (2009b). The Furan Counterpart of Poly(Ethylene Terephthalate): An Alternative Material Based on Renewable Resources. Journal of Polymer Science Part a-Polymer Chemistry, 47, 295-298.

Holladay, J. E., Werpy, T. A. and Muzatko, D. S. (2004). Catalytic Hydrogenation of Glutamic Acid. Applied Biochemistry and Biotechnology, 113, 857-869.

Kumar, G. S. and Nanthini, R. (2009). Synthesis and Characterization of AliphaticAromatic Random Copolyester/Clay Nano-Biocomposites. High Performance Polymers, 22, 131-144.

Ma, J., Pang, Y., Wang, M., Xu, J., Ma, H. and Nie, X. (2012). The Copolymerization Reactivity of Diols with 2,5Furandicarboxylic Acid for Furan-Based Copolyester Materials. Journal of Materials Chemistry, 22, 3457-3461.

Mitiakoudis, A. and Gandini, A. (1991). Synthesis and Characterization of Furanic Polyamides. Macromolecules, 24, 830835.

Nasirudeen, M. B., Hailes, H. C. and Evans, J. R. G. (2017). Preparation of 5Hydroxymethylfurfural from Glucose and Fructose in lonic Liquids by Reactive Vacuum Distillation over a Solid Catalyst. Current Organic Synthesis, 14, 596-603.

Ramesh, H. P. and Tharanathan, R. N. (2003). Carbohydrates - the Renewable Raw Materials of High Biotechnological Value. Critical Reviews in Biotechnology, 23, 149-173.

Ray, S. S. and Okamoto, M. (2003). Polymer/Layered Silicate 
Nanocomposites: A Review from Preparation to Processing. Progress in Polymer Science, 28, 1539-1641.

Silverstein, R., Webster, F. and Kiemle, D. (2005a). Spectrometric Identification of Organic Compounds. Hoboken: John Wiley \& Sons Inc.

Silverstein, R., Webster, F. and Kiemle, D. (2005b). Spectrometric Identification of Organic Compounds, John Wiley \& Sons, Inc., Hoboken, pp. 72-126.

Werpy, T., Petersen, G., Aden, A., Bozell, J., Holladay, J., White, J. and Jones, S. (2004). Top Value Added Chemicals from Biomass. Volume 1-Results of Screening for Potential Candidates from Sugars and Synthesis Gas (No. Doe/Go-1020041992). U.S Department of Energy, Washington DC
Yoshida, S., Hiraga, K., Takehana, T., Taniguchi, I., Yamaji, H., Maeda, Y., Toyohara, K., Miyamoto, K., Kimura, Y. and Oda, K. (2016). A Bacterium That Degrades and Assimilates Poly(Ethylene Terephthalate). Science, 351, 1196.

Zhu, J. H., Cai, J. L., Xie, W. C., Chen, P. H., Gazzano, M., Scandola, M. and Gross, R. A. (2013). Poly(Butylene 2,5-Furan Dicarboxylate), a Biobased Alternative to Pbt: Synthesis, Physical Properties, and Crystal Structure. Macromolecules, 46, 796-804. 